\title{
SHORT COMMUNICATION PTX3 genetic variations affect the risk of Pseudomonas aeruginosa airway colonization in cystic fibrosis patients
}

\author{
M Chiarini ${ }^{1}$, C Sabelli ${ }^{1}$, P Melotti ${ }^{2}$, C Garlanda ${ }^{3}$, G Savoldi ${ }^{1}$, C Mazza ${ }^{1}$, R Padoan ${ }^{1}$, A Plebani ${ }^{1}$, \\ A Mantovani ${ }^{3,4}$, LD Notarangelo ${ }^{1}$, BM Assael $^{2}$ and R Badolato ${ }^{1}$ \\ ${ }^{1}$ Clinica Pediatrica, Istituto di Medicina Molecolare 'Angelo Nocivelli', Universita' di Brescia, Brescia, Italy; ${ }^{2}$ Cystic Fibrosis Center, Verona, \\ Italy; ${ }^{3}$ Istituto Clinico Humanitas IRCCS, Rozzano, Italy and ${ }^{4}$ Department of Translational Medicine, University of Milan, Milan, Italy
}

\begin{abstract}
Cystic fibrosis (CF) is a common life-threatening autosomal recessive disorder in the Caucasian population, and the gene responsible is the CF transmembrane conductance regulator (CFTR). Patients with CF have repeated bacterial infection of the airways caused by Pseudomonas aeruginosa (PA), which is one of the predominant pathogen, and endobronchial chronic infection represents a major cause of morbidity and mortality. Pentraxin 3 (PTX3) is a gene that encodes the antimicrobial protein, PTX3, which is believed to have an important role in innate immunity of lung. To address the role of $P T X 3$ in the risk of $P A$ lung colonization, we investigated five single nucleotide polymorphisms of PTX3 gene in 172 Caucasian CF patients who were homozygous for the F508del mutation. We observed that PTX3 haplotype frequencies were significantly different between patients with PA colonization, as compared with noncolonized patients. Moreover, a protective effect was found in association with a specific haplotype (odds ratio 0.524). Our data suggest that variations within PTX3 affect lung colonization of Pseudomonas in patients with CF.
\end{abstract}

Genes and Immunity (2010) 11, 665-670; doi:10.1038/gene.2010.41; published online 7 October 2010

Keywords: cystic fibrosis; Pseudomonas aeruginosa; modifier genes; gene polymorphism; pentraxin 3; innate immunity

Cystic fibrosis (CF) is a complex condition affecting a number of organs, including the exocrine pancreas, intestine, sweat glands and lung; the effects of the latter are the major cause of disease morbidity and early mortality. Identification of the CF transmembrane conductance regulator (CFTR) gene in $1989^{1}$ was followed by discovery of hundreds of mutant CFTR alleles (CFTR database on www.genet.sickkids.on.ca/) and by attempts at genotype-phenotype correlations. ${ }^{2}$ The associations between CFTR genotype and exocrine pancreatic and sweat gland phenotypes were soon found to be greater than the association between CFTR genotype and the pulmonary phenotype. ${ }^{2,3}$ The clinical outcome of pulmonary disease in CF patients is extremely variable, even among patients with the same CFTR genotype. This variability could arise from some combination of environmental and modifier gene effects.

Patients with CF have repeated bacterial infection of the airways since the first month of life; Pseudomonas aeruginosa (PA) is one of the predominant pathogen and can lead to endobronchial chronic infection. Pathogen recognition is one of the key mechanisms of innate immunity, and is mediated by transmembrane, cytosolic and secreted soluble pattern recognition receptors. ${ }^{4}$

Correspondence: Dr R Badolato, Clinica Pediatrica, Istituto di Medicina Molecolare, University of Brescia, P.le Spedali Civili 1, Brescia 25123, Italy.

E-mail: badolato@med.unibs.it

Received 23 February 2010; revised 7 June 2010; accepted 18 June 2010; published online 7 October 2010
Pentraxin 3 (PTX3) is a prototypic long pentraxin that has a nonredundant role in the antimicrobial response against multiple pathogens including PA. ${ }^{5}$

Pentraxins are a superfamily of conserved proteins that are characterized by a cyclic multimeric structure, usually pentameric structure. ${ }^{6-9}$ The classical short pentraxins, C-reactive protein and serum amyloid P component, are acute-phase proteins produced in the liver in response to inflammatory mediators. PTX3 shares similarities with the classical short pentraxins; however, it has an unrelated long amino-terminal domain coupled to the carboxyterminal pentraxin domain, and differs in gene organization, cellular source and ligands recognition. ${ }^{9}$ PTX3 is rapidly produced and released by several cell types, in particular by mononuclear phagocytes, dendritic cells, fibroblasts and endothelial cells, ${ }^{9-11}$ in response to primary inflammatory signals. PTX3 binds the complement component $\mathrm{C} 1 \mathrm{q}$, the extracellular matrix component tumor necrosis factor- $\alpha$-induced protein 6 and selected microorganisms such as PA with high affinity.

Studies in PTX3-deficient mice suggest that PTX3 has a role in innate resistance to bacterial infection, such as PA. Lung infection of PTX3-deficient mice by PA showed an increase in mortality and lung colonization. ${ }^{12}$ Moreover, a role for PTX3 gene, as potential modifier, has been hypothesized for susceptibility to pulmonary tuberculosis in an African population. ${ }^{13}$

The human PTX3 gene, localized on human chromosome 3 band q25, is organized in three exons separated by two introns and covers $\sim 7 \mathrm{~Kb}$ (Figure 1 ). We analyzed five single nucleotide polymorphisms (SNPs) of PTX3, 
(without including any other gene in the analysis), which included three intronic (rs2305619, rs1840680 and rs3845978) and two exonic (synonymous mutation in rs35948036, nonsynonymous mutation in rs3816527) (Table 1) SNPs. The allelic frequency in Caucasian population for the SNPs rs2305619, rs3594S036 and rs3845978 was reported in NCBI database, whereas SNPs rs1840680 and rs3816527 were validated by our group in a control population.

In this work, we analyzed the role of five SNPs of PTX3 in 127 CF Caucasian patients homozygous for F508del (age $\geqslant 11$ years), for the development of chronic PA colonization.

The genotype-allele distribution for PTX3 polymorphisms followed the Hardy-Weinberg equilibrium, and allelic frequencies were comparable among patients and controls (Table 2a). Allelic distribution of five PTX3 polymorphisms was analyzed in $75 \mathrm{CF}$ patients with chronic PA colonization (PA patients), as compared with 52 subjects without evidence of persistent PA growth in bronchial secretions (non-PA patients) (Table 2b). Analysis of SNPs frequencies in CF patients has shown that distribution of two intronic SNPs (rs1840680 and rs2305619) and one exonic SNP (rs3816527) were different between group of patients with or without PA chronic colonization. In particular, statistical analysis has shown that the intronic rs2305619 and rs1840680 alleles

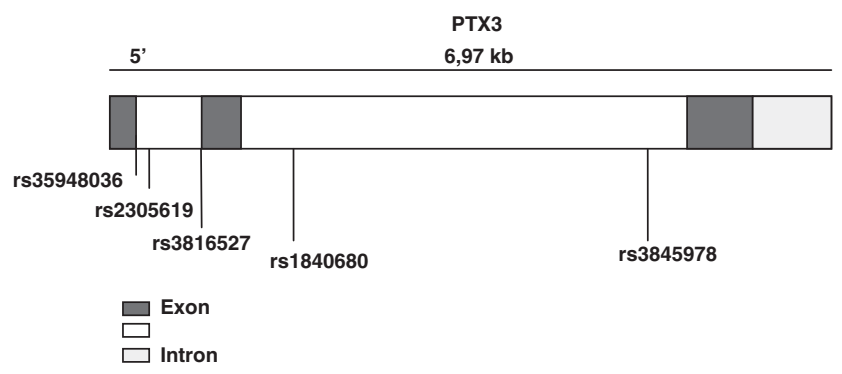

Figure 1 PTX3 gene maps with position of SNPs.

Table 1 Single nucleotide polymorphism (SNP) information

\begin{tabular}{lllcc}
\hline SNP ID & Alleles & $\begin{array}{l}\text { Peptide } \\
\text { shift }\end{array}$ & $\begin{array}{c}\text { Synonymous } \\
\text { change }\end{array}$ & $\begin{array}{c}\text { Peptide } \\
\text { location (aa) }\end{array}$ \\
\hline rs2305619 & A/G & & & \\
rs3816527 & C/A & Ala $\rightarrow$ Asp & No & 48 \\
rs1840680 & A/G & & & \\
rs3845978 & C/T & None (Leu) & Yes & 16 \\
rs35948036 & C/T & Nou & \\
\hline
\end{tabular}

Abbreviations: Ala, alanine; Asp, aspartic acid; Leu, leucine. We examined 127 (70 females, 57 males, age range, 11-52 years) Caucasian patients homozygous for the F508del mutation, who were followed up at the Regional Cystic Fibrosis centre of Verona (Italy). The study protocol was approved by Verona Azienda Ospedaliera and Brescia Spedali Civili Ethics Committees. Patients and parents of minors provided written informed consent. Clinical, biological and functional data were obtained retrospectively from patients' hospital records. To validate allelic frequencies of SNPs in our population, we have collected cord blood samples from a total of 165 children (72 females, 93 males) from the Department of Obstetrics at Spedali Civili of Brescia.
Table 2a Frequency distributions of PTX3 gene single nucleotide polymorphisms (SNPs) in patients and controls

\begin{tabular}{lccccc}
\hline SNPS & $\begin{array}{c}\text { Associated } \\
\text { allele }\end{array}$ & $\begin{array}{c}\text { Frequencies in } \\
C F \text { patients } \\
(n=127)\end{array}$ & $\begin{array}{c}\text { Frequencies } \\
\text { in controls } \\
(n=165)\end{array}$ & $\chi^{2}$ & P-value \\
\hline rs2305619 & $\mathrm{A}$ & 0.508 & 0.461 & 1.285 & 0.257 \\
rs1840680 & $\mathrm{A}$ & 0.504 & 0.448 & 1.771 & 0.183 \\
rs3845978 & $\mathrm{T}$ & 0.028 & 0.027 & 0.000 & 0.983 \\
rs35948036 & $\mathrm{C}$ & 0.016 & 0.000 & 5.233 & 0.022 \\
rs3816527 & $\mathrm{C}$ & 0.453 & 0.397 & 1.832 & 0.176 \\
\hline
\end{tabular}

Abbreviations: CF, cystic fibrosis; CFTR, CF transmembrane conductance regulator; PTX3, pentraxin 3.

All DNA samples were extracted using a standard salting out procedure. DNA samples were estimated by a spectrophotometer and final concentrations were determined. Samples were genotyped by TaqMan SNP assay ( $5 \mathrm{ng}$ of DNA in $25 \mu \mathrm{l}$ reaction volume; Applied Biosystems, Carlsbad, CA, USA) using ABI PRISM 7000 Sequence Detection System. Fluorescence curves were analyzed with the 7000 Sequence Detection Software v.1.1 for allelic discrimination. All samples were analyzed for five SNPs in PTX3, including three intronic (rs2305619, rs1840680 and rs3845978) and two exonic (synonymous mutation in rs35948036, D48A nonsynonymous mutation in rs3816527) SNPs. The diagnosis of CF was established on the basis of the results of two sweat chloride tests $\left(>60 \mathrm{mmoll}^{-1}\right)$, performed according to Gibson and Cooke ${ }^{22}$ and the identification of mutations in the CFTR gene.

Table $\mathbf{2 b}$ Frequency distributions of PTX3 gene single nucleotide polymorphisms (SNPs) in patients with (PA) and without (non-PA) PA colonization

\begin{tabular}{lccccc}
\hline SNPS & $\begin{array}{c}\text { Associated } \\
\text { allele }\end{array}$ & $\begin{array}{c}\text { Frequencies in } \\
\text { PA patients } \\
(n=75)\end{array}$ & $\begin{array}{c}\text { Frequencies } \\
\text { in non-PA } \\
\text { patients } \\
(n=52)\end{array}$ & $\chi^{2}$ & P-value \\
\hline $\mathrm{rs} 2305619$ & $\mathrm{~A}$ & 0.573 & 0.413 & 6.281 & 0.012 \\
$\mathrm{rs} 1840680$ & $\mathrm{~A}$ & 0.567 & 0.413 & 5.767 & 0.016 \\
$\mathrm{rs3845978}$ & $\mathrm{C}$ & 0.980 & 0.962 & 0.781 & 0.377 \\
$\mathrm{rs35948036}$ & $\mathrm{C}$ & 0.020 & 0.010 & 0.467 & 0.513 \\
$\mathrm{rs3816527}$ & $\mathrm{C}$ & 0.507 & 0.375 & 4.297 & 0.038 \\
\hline
\end{tabular}

Abbreviations: CF, cystic fibrosis; PTX3, pentraxin 3. The Pseudomonas aeruginosa (PA) colonization was defined as the presence of $\mathrm{PA}$ in at least three consecutive sputum cultures collected in a 6-month period. To have an adequate clinical history, we have selected CF patients who were $\geqslant 11$ years old. Age at the time of first PA colonization is reported for each patient with bacterial colonization (75 patients: 39 females, 36 males; age range, 11-45 years), whereas chronological age at the time of the study is reported for patients without PA colonization (52 patients: 31 females, 21 males; age range, 11-52 years). The two groups of patients were comparable for age (CF with PA colonization $20.5 \pm 0.78$ years versus CF without PA colonization $23.3 \pm 1.37$ years) and for sociodemographic variables. The two groups of patients were followed up in the same time periods, thus undergoing similar protocols of eradications of PA. As a definition of chronic colonization, we adopted the most widely accepted, that is, presence of Pseudomonas in sputum, in three samples obtained in a period of 1 year. Chronic colonization was not reversible in our patients. On the other hand, patients not colonized by PA were consistently found Pseudomonas-free and did not undergo specific anti-Pseudomonas treatments in the attempt to eradicate the germ. To correct for multiple testing, we performed 1000 permutations (HaploView 4.2). 
Table 3 Genotype distribution of SNPs in PA and non-PA patients

\begin{tabular}{|c|c|c|c|c|c|c|}
\hline & \multirow[t]{2}{*}{ Model } & & \multicolumn{2}{|c|}{ Frequency (\%) } & \multirow[t]{2}{*}{ OR $(95 \% C I)$} & \multirow[t]{2}{*}{ P-value } \\
\hline & & & $P A$ & Not $P A$ & & \\
\hline \multirow[t]{7}{*}{ rs35948036 } & \multirow[t]{3}{*}{ Codominant } & $\mathrm{T} / \mathrm{T}$ & $73(97.4)$ & $51(98.1)$ & Reference category & \multirow[t]{3}{*}{0.570} \\
\hline & & $\mathrm{C} / \mathrm{T}$ & $1(1.3)$ & $1(1.9)$ & $1.43(0.09-23.42)$ & \\
\hline & & $\mathrm{C} / \mathrm{C}$ & $1(1.3)$ & $0(0)$ & 0.00 (0.00-NA) & \\
\hline & \multirow[t]{2}{*}{ Dominant } & $\mathrm{T} / \mathrm{T}$ & 73 (97.3) & $51(98.1)$ & Reference category & \multirow[t]{2}{*}{0.780} \\
\hline & & $\mathrm{C} / \mathrm{T}-\mathrm{C} / \mathrm{C}$ & $2(2.7)$ & $1(1.9)$ & $0.72(0.06-8.11)$ & \\
\hline & \multirow[t]{2}{*}{ Recessive } & $\mathrm{T} / \mathrm{T}-\mathrm{C} / \mathrm{T}$ & 74 (98.7) & $52(100)$ & Reference category & \multirow[t]{2}{*}{0.300} \\
\hline & & $\mathrm{C} / \mathrm{C}$ & $1(1.3)$ & $0(0)$ & $0.00(0.00-\mathrm{NA})$ & \\
\hline \multirow[t]{7}{*}{ rs2305619 } & \multirow[t]{3}{*}{ Codominant } & $\mathrm{A} / \mathrm{A}$ & $27(36)$ & $9(17.3)$ & Reference category & \multirow[t]{3}{*}{0.045} \\
\hline & & $\mathrm{A} / \mathrm{G}$ & $32(42.7)$ & $25(48.1)$ & $2.34(0.94-5.87)$ & \\
\hline & & $\mathrm{G} / \mathrm{G}$ & $16(21.3)$ & 18 (34.6) & $3.37(1.23-9.28)$ & \\
\hline & \multirow[t]{2}{*}{ Dominant } & $\mathrm{A} / \mathrm{A}$ & $27(36)$ & 9 (17.3) & Reference category & \multirow[t]{2}{*}{0.019} \\
\hline & & $\mathrm{A} / \mathrm{G}-\mathrm{G} / \mathrm{G}$ & $48(64)$ & $43(82.7)$ & $2.69(1.14-6.35)$ & \\
\hline & \multirow{2}{*}{ Recessive } & $\mathrm{A} / \mathrm{A}-\mathrm{A} / \mathrm{G}$ & 59 (78.7) & $34(65.4)$ & Reference category & \multirow{2}{*}{0.098} \\
\hline & & $\mathrm{G} / \mathrm{G}$ & $16(21.3)$ & 18 (34.6) & $1.95(0.88-4.32)$ & \\
\hline \multirow[t]{7}{*}{ rs3816527 } & \multirow[t]{3}{*}{ Codominant } & $\mathrm{A} / \mathrm{A}$ & $20(26.7)$ & $21(40.4)$ & Reference category & \multirow[t]{3}{*}{0.130} \\
\hline & & $\mathrm{A} / \mathrm{C}$ & $34(45.3)$ & $23(44.2)$ & $0.64(0.26-1.45)$ & \\
\hline & & $\mathrm{C} / \mathrm{C}$ & $21(28)$ & $8(15.4)$ & $0.36(0.13-1.01)$ & \\
\hline & \multirow{2}{*}{ Dominant } & $\mathrm{A} / \mathrm{A}$ & $20(26.7)$ & $21(40.4)$ & Reference category & \multirow{2}{*}{0.110} \\
\hline & & $\mathrm{A} / \mathrm{C}-\mathrm{C} / \mathrm{C}$ & $55(73.3)$ & $31(59.6)$ & $0.54(0.25-1.14)$ & \\
\hline & \multirow[t]{2}{*}{ Recessive } & $\mathrm{A} / \mathrm{A}-\mathrm{A} / \mathrm{C}$ & $54(72)$ & $44(84.6)$ & Reference category & \multirow[t]{2}{*}{0.090} \\
\hline & & $\mathrm{C} / \mathrm{C}$ & $21(28)$ & $8(15.4)$ & $0.47(0.19-1.16)$ & \\
\hline \multirow[t]{7}{*}{ rs1840680 } & \multirow[t]{3}{*}{ Codominant } & $\mathrm{A} / \mathrm{A}$ & $26(34.7)$ & $9(17.3)$ & Reference category & \multirow[t]{3}{*}{0.059} \\
\hline & & $\mathrm{A} / \mathrm{G}$ & $33(44)$ & $25(48.1)$ & $2.19(0.87-5.49)$ & \\
\hline & & G/G & $16(21.3)$ & 18 (34.6) & $3.25(1.18-8.69)$ & \\
\hline & \multirow{2}{*}{ Dominant } & $\mathrm{A} / \mathrm{A}$ & $26(34.7)$ & 9 (17.3) & Reference category & \multirow[t]{2}{*}{0.028} \\
\hline & & $\mathrm{A} / \mathrm{G}-\mathrm{G} / \mathrm{G}$ & $49(65.3)$ & $43(82.7)$ & $2.54(1.07-6.00)$ & \\
\hline & Recessive & $\mathrm{A} / \mathrm{A}-\mathrm{A} / \mathrm{G}$ & 59 (78.7) & $34(65.4)$ & Reference category & 0.098 \\
\hline & & $\mathrm{G} / \mathrm{G}$ & $16(21.3)$ & $18(34.6)$ & $1.95(0.88-4.32)$ & \\
\hline rs3845978 & - & $\mathrm{C} / \mathrm{C}$ & $72(96)$ & $48(92.3)$ & Reference category & 0.370 \\
\hline & & $\mathrm{C} / \mathrm{T}$ & $3(4)$ & $4(7.7)$ & $2.00(0.43-9.34)$ & \\
\hline
\end{tabular}

Abbreviations: CI, confidence interval; NA, not applicable; OR, odds ratio; PA, Pseudomonas aeruginosa; SNP, single nucleotide polymorphism.

and the exonic allele rs3816527 are statistically associated ( $\chi^{2}$-test: $P=0.012, P=0.016$ and $P=0.038$, respectively) with PA colonization. However, after permutation test (1000 permutations), PA colonization was significantly associated only with rs2305619.

Analysis of distribution of SNP genotypes among patients (Table 3) has revealed a recessive model for exonic SNPs (rs35948036 and rs3816527) and a dominant model for intronic SNPs (rs2305619 and rs1840680). Although we could not define the phenotype model for the intronic SNP, rs3845978, because the genotype T/T was not observed in our patients group, calculation of odds ratio (OR) values on the basis of a dominant model for SNPs rs2305619 $(\mathrm{OR}=2.69 ; 95 \%$ confidence interval (CI): 1.14-6.35) and rs1840680 (OR $=2.54$; 95\% CI: $1.07-$ 6.00) have shown a positive association with PA colonization, suggesting that these SNPs might increase the risk of bacterial colonization in $\mathrm{CF}$ patients. In contrast, calculation of OR on the basis of a recessive model for exonic SNPs rs35948036 (OR $=0.72,95 \%$ $\mathrm{CI}=0.06-8.11)$ and $\mathrm{rs} 3816527(\mathrm{OR}=0.54,95 \% \mathrm{CI}=0.25-$ 1.14) suggests that these genotypes might be protective for PA colonization.

Next, we have compared the haplotype frequencies between PA patients and non-PA patients (Table 4). We observed that the two haplotypes, T-A-G-A-G and T-A-
C-A-C (SNPs position: rs35948036-rs2305619-rs3816527rs1840680-rs3845678) are significantly associated (T-G-AG-C, $P=0.016$; T-A-C-A-C, $P=0.037$ ). In particular, we observed that T-G-A-G-C haplotype was present in $54.6 \%$ of CF patients not colonized by PA, as compared with $39.3 \%$ of PA-colonized patients. In contrast, the haplotype T-A-C-A-C was present at higher frequency in PA patients $(50.0 \%)$, as compared with noncolonized patients $(36.8 \%)$. After permutation test, no haplotype association preserved a significant $P$-value; therefore, haplotype analysis was restricted to a sub-group of SNPs. Firstly, we have analyzed the haplotype that included the three SNPs associated with PA colonization (intronic SNPs rs2305619 and rs1840680, exonic SNP rs3816527). Analysis of the G-A-G haplotype has shown that this haplotype $\left(P\right.$-value $\left.=0.012, \chi^{2}=6.281\right)$ was present in $58.7 \%$ of non-PA patients $(42.7 \%$ of PA patients), whereas the A-C-A haplotype $(P$-value $=0.038$, $\chi^{2}=4.297$ ) was more common in PA patients $(50.7 \%)$, as compared with non-PA colonized patients (37.5\%). After permutation test, G-A-G haplotype preserved a significant $P$-value (0.030). Secondly, we have added the other exonic SNP rs35948036 to the analysis of these three SNPs (rs2305619, rs1840680 and rs3816527). Even after this analysis, we observed a similar trend. The T-GA-G haplotype $(P$-value $=0.007)$ was more common in 
Table 4 PTX3 haplotype trend regression results for extended haplotypes

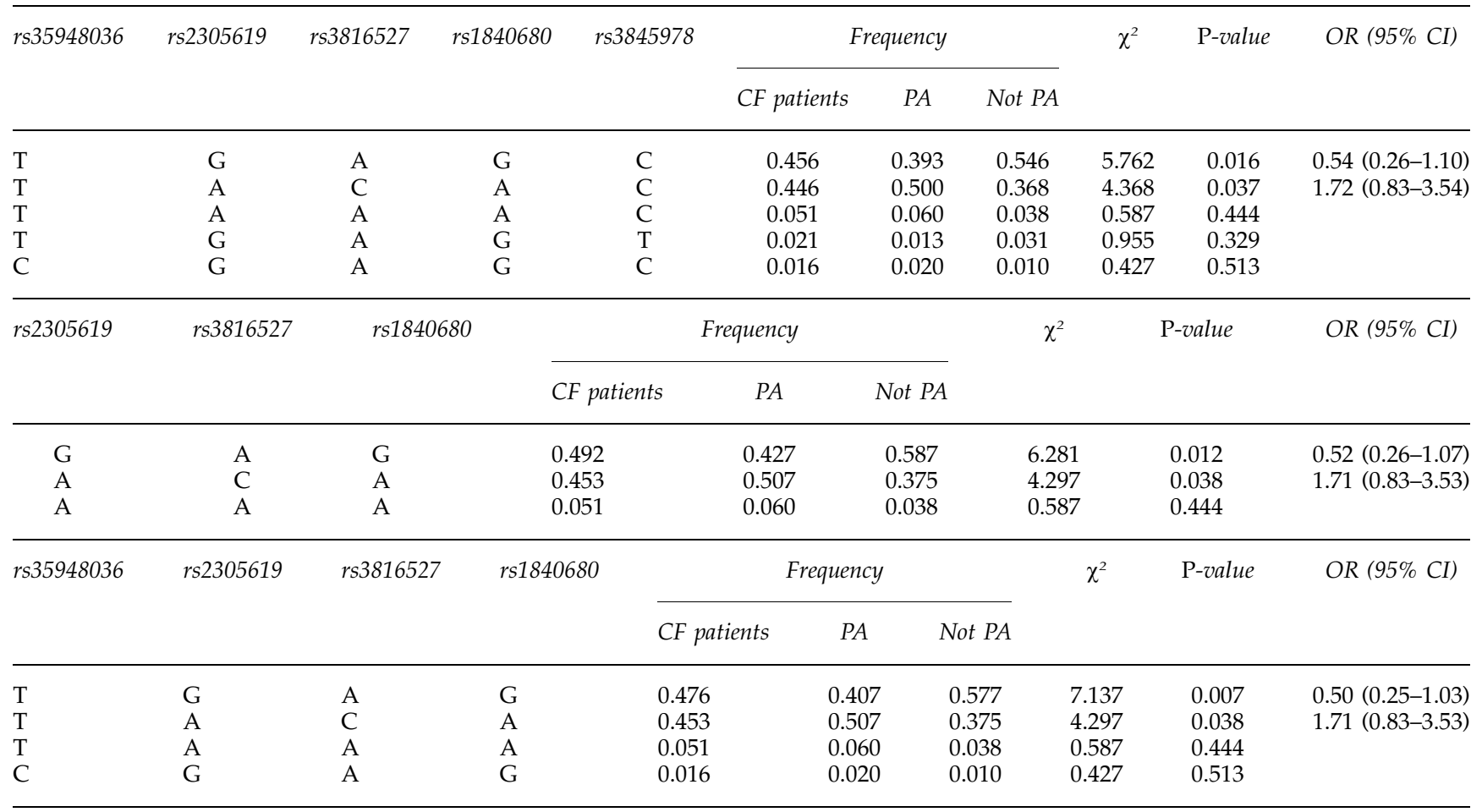

Abbreviations: CF, cystic fibrosis; CI, confidence interval; OR, odds ratio; PA, Pseudomonas aeruginosa; PTX3, pentraxin 3; SNP, single nucleotide polymorphism.

Statistical analysis has shown significant association of the haplotypes, as indicated above. To correct for multiple testing, we performed 1000 permutations using HaploView 4.2; statistical significance was preserved for the G-A-G and the T-G-A-G haplotypes.

noncolonized patients $(57.7 \%)$ than in PA-colonized patients $(40.7 \%)$, whereas, the T-A-C-A haplotype ( $P$ value $=0.038)$ was present in $50.7 \%$ of PA patients, as compared with $37.5 \%$ of non-PA patients. After permutation test, the T-G-A-G haplotype preserved a significant $P$-value (0.029). Haplotype trend regression analyses were followed by linkage disequilibrium analysis within PTX3 gene, using the HaploView software (Broad Institute, Cambridge, MA, USA; Figure 2).

We have observed a significant association of one PTX3 polymorphism with chronic PA lung colonization in CF patients with homozygous F508del CFTR mutation. A haplotype association in PTX3 gene was also identified in these patients, suggesting that PTX3 protein is involved in preventing lung colonization by this opportunistic pathogen in CF patients. A previous study by Olesen et al. ${ }^{13}$ reported an association of the same PTX3 haplotype with pulmonary tuberculosis risk in West Africa, in particular, a lower frequency of the rs2305619, rs3816527 and rs1840680 SNPs was observed in patients with pulmonary tuberculosis, as compared with control population. The results of our study, which will need further confirmations, suggest that the same haplotype (rs2305619, rs3816527 and rs1840680) was protective for risk of lung colonization by $\mathrm{PA}$ in $\mathrm{CF}$ patients. These observations sustain the hypothesis that the long pentraxin PTX3 has a nonredundant function in microbial recognition and subsequent clearance of microbial pathogens of the lower respiratory tract, including PA and Mycobacterium tuberculosis. PTX3 is stored in specific granules of neutrophils and in other
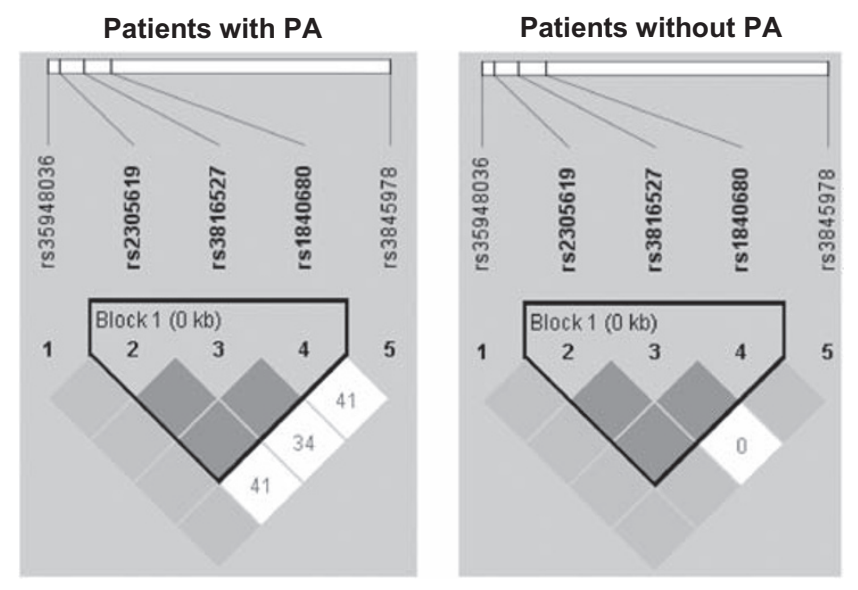

Figure 2 HaploView figures. Linkage disequilibrium (LD) plots characterizing haplotype blocks in PTX3 gene. In the first column are LD plots for PA colonization patients and in the second column are LD plots for patients without PA colonization. $\mathrm{D}^{\prime}$ values are indicated in percentages within squares in the LD plot, with solid blocks without numbers indicating $\mathrm{D}^{\prime}=1(100 \%)$ for the corresponding pair of variants. Strong LD is indicated by dark gray, whereas light gray and white indicate uninformative and low confidence values, respectively. LD Blocks were created with the default algorithm in HaploView that creates $95 \%$ confidence bounds on $\mathrm{D}^{\prime}$ considered to be in strong $\mathrm{LD}$, where $95 \%$ of the comparisons made are informative. The haplotype blocks were created using HaploView program, version 4.2.

intracellular storage compartments of dendritic cells and monocytes, ready to be released in response to inflammatory and/or microbial stimuli. ${ }^{14}$ Once PTX3 is 
released in the extracellular space, it can bind specific pathogens such as fungi, bacteria and viruses, promoting their phagocytosis and removal from tissues. ${ }^{15,16}$

Although the clinical heterogeneity of lung disease in CF patients with the same CFTR mutation is related to multiple genetic and environmental factors, it is currently well established that chronic lung colonization by PA represents an important determinant for the progression of lung damage in CF patients. Because we have observed that a specific haplotype of PTX3 gene is associated with chronic PA colonization of the lung in CF patients, it is likely that the genetic variants of PTX3 might ultimately influence the severity of CF lung disease. However, we failed to detect in our cohort of $\mathrm{CF}$ patients any correlation of respiratory parameters, including FEV1, with any PTX3 gene polymorphisms, suggesting that the contribution of these genetic variants to lung disease progression needs to be investigated in a larger sample of CF patients. This observation is in agreement with a previous report by Tesse et al. ${ }^{17}$, showing that specific gene polymorphisms of the DEFB1 gene encoding for the antimicrobial peptide $\beta$-defensin- 1 are associated with chronic PA colonization, but do not correlate with abnormal lung function parameters. Other investigators have sought to associate genetic variations in genes encoding for cytokines with a key role in inflammatory response with lung disease progression in CF. ${ }^{18}$ However, no genetic variants of the genes encoding for cytokines such as tumor necrosis factor- $\alpha$, lymphotoxin- $\alpha$, interleukin (IL) $1-\beta$, IL-1 receptor antagonist, IL-6, IL- 8 and IL-10 were linked with impairment of lung function. ${ }^{18}$ Although variants in the gene encoding for the transforming growth factor- $\beta 1$ were associated with lung function decline in a large cohort of CF patients, it was not confirmed in a smaller cohort. ${ }^{19}$

Analysis of genetic variants in the mannose-binding lectin $(M B L)$ gene in children and adults with $C F$ has revealed that adult patients who were homozygous for the rare variant of $\mathrm{MBL}$ had significantly reduced survival, as compared with patients carrying the common genotypes. ${ }^{20}$ However, this association of MBL variants with lung functions was not reproducible in the pediatric cohort, unless after correction for confounding factors. ${ }^{21}$ Similarly, the use of proportional hazards regression models has shown that in patients carrying specific IL-8 variants, PA chronic colonization occurs at an older age of 18 years, suggesting a protective effect of this gene against lung disease progression.

It is interesting that all the studies seeking to establish a correlation between lung disease progression and/or PA chronic colonization with genetic variants of modifier genes have revealed a key role for genes encoding antimicrobial proteins such as DEFB, MBL and PTX3, or for $I L-8$, which encodes for the neutrophil chemotactic protein IL-8. Because all these antimicrobial proteins and the chemotactic factor IL-8 are released in large amounts during lung infections, it is conceivable to hypothesize that their genetic variants might confer susceptibility/ resistance against common opportunistic pathogens that are isolated from CF patients with respiratory infection.

\section{Conflict of interest}

The authors declare no conflict of interest.

\section{Acknowledgements}

We thank Dr Chiara Magri for critically evaluating the paper. This work was supported by grants from Telethon GGP05095, Fondazione Cariplo NOBEL Grant, EU grant FP7 HLH-cure (project no. 201461), e-rare EU grant, Rare Diseases-ISS project, PRIN 2007 no. 2007ACZMMZ_005, Associazione Davide Rodella Onlus.

\section{References}

1 Kerem B, Rommens JM, Buchanan JA, Markiewicz D, Cox TK, Chakravarti A et al. Identification of the cystic fibrosis gene: genetic analysis. Science 1989; 245: 1073-1080.

2 Kerem E, Corey M, Kerem BS, Rommens J, Markiewicz D, Levison $\mathrm{H}$ et al. The relation between genotype and phenotype in cystic fibrosis-analysis of the most common mutation (delta F508). N Engl J Med 1990; 323: 1517-1522.

3 Kristidis P, Bozon D, Corey M, Markiewicz D, Rommens J, Tsui LC et al. Genetic determination of exocrine pancreatic function in cystic fibrosis. Am J Hum Genet 1992; 50: 1178-1184.

4 Medzhitov R. Toll-like receptors and innate immunity. Nat Rev Immunol 2001; 1: 135-145.

5 Diniz SN, Nomizo R, Cisalpino PS, Teixeira MM, Brown GD, Mantovani A et al. PTX3 function as an opsonin for the dectin1-dependent internalization of zymosan by macrophages. J Leukoc Biol 2004; 75: 649-656.

6 Pepys MB, Baltz ML. Acute phase proteins with special reference to $C$-reactive protein and related proteins (pentaxins) and serum amyloid A protein. Adv Immunol 1983; 34: 141-212.

7 Suffredini AF, Fantuzzi G, Badolato R, Oppenheim JJ, O'Grady NP. New insights into the biology of the acute phase response. J Clin Immunol 1999; 19: 203-214.

8 Baumann H, Gauldie J. The acute phase response. Immunol Today 1994; 15: 74-80.

9 Garlanda C, Bottazzi B, Bastone A, Mantovani A. Pentraxins at the crossroads between innate immunity, inflammation, matrix deposition, and female fertility. Annu Rev Immunol 2005; 23: 337-366.

10 Doni A, Peri G, Chieppa M, Allavena P, Pasqualini F, Vago L et al. Production of the soluble pattern recognition receptor PTX3 by myeloid, but not plasmacytoid, dendritic cells. Eur J Immunol 2003; 33: 2886-2893.

11 Nauta AJ, de Haij S, Bottazzi B, Mantovani A, Borrias MC, Aten $\mathrm{J}$ et al. Human renal epithelial cells produce the long pentraxin PTX3. Kidney Int 2005; 67: 543-553.

12 Garlanda C, Hirsch E, Bozza S, Salustri A, De Acetis M, Nota $\mathrm{R}$ et al. Non-redundant role of the long pentraxin PTX3 in anti-fungal innate immune response. Nature 2002; 420: 182-186.

13 Olesen R, Wejse C, Velez DR, Bisseye C, Sodemann M, Aaby P et al. DC-SIGN (CD209), pentraxin 3 and vitamin D receptor gene variants associate with pulmonary tuberculosis risk in West Africans. Genes Immun 2007; 8: 456-467.

14 Jaillon S, Peri G, Delneste Y, Fremaux I, Doni A, Moalli F et al. The humoral pattern recognition receptor PTX3 is stored in neutrophil granules and localizes in extracellular traps. J Exp Med 2007; 204: 793-804.

15 Garlanda C, Hirsch E, Bozza S, Salustri A, De Acetis M, Nota $\mathrm{R}$ et al. Non-redundant role of the long pentraxin PTX3 in anti-fungal innate immune response. Nature 2002; 420: 182-186.

16 Jeannin P, Bottazzi B, Sironi M, Doni A, Rusnati M, Presta M et al. Complexity and complementarity of outer membrane protein A recognition by cellular and humoral innate immunity receptors. Immunity 2005; 22: 551-560.

17 Tesse R, Cardinale F, Santostasi T, Polizzi A, Manca A, Mappa $\mathrm{L}$ et al. Association of beta-defensin-1 gene polymorphisms 
with Pseudomonas aeruginosa airway colonization in cystic fibrosis. Genes Immun 2008; 9: 57-60.

18 Corvol H, Boelle PY, Brouard J, Knauer N, Chadelat K, Henrion-Caude A et al. Genetic variations in inflammatory mediators influence lung disease progression in cystic fibrosis. Pediatr Pulmonol 2008; 43: 1224-1232.

19 Brazova J, Sismova K, Vavrova V, Bartosova J, Macek Jr M, Lauschman $\mathrm{H}$ et al. Polymorphisms of TGF-beta 1 in cystic fibrosis patients. Clin Immunol 2006; 121: 350-357.

20 Garred P, Pressler T, Madsen HO, Frederiksen B, Svejgaard A, Hoiby $\mathrm{N}$ et al. Association of mannosebinding lectin gene heterogeneity with severity of lung disease and survival in cystic fibrosis. J Clin Invest 1999; 104: 431-437.
21 McDougal KE, Green DM, Vanscoy LL, Fallin MD, Grow M, Cheng $\mathrm{S}$ et al. Use of a modeling framework to evaluate the effect of a modifier gene (MBL2) on variation in cystic fibrosis. Eur J Hum Genet 2010; 18: 680-684.

22 Gibson LE, Cooke RE. A test for concentration of electrolytes in sweat in cystic fibrosis of the pancreas utilizing pilocarpine by iontophoresis. Pediatrics 1959; 23: 545-549.

This work is licensed under the Creative Commons Attribution-NonCommercial-Share Alike 3.0 Unported License. To view a copy of this license, visit http://creativecommons.org/licenses/by-nc-sa/3.0/ 